\title{
The Impact of Closed-mindedness on the Assessment of Threat: An Empirical Study
}

\author{
Colin A Wastell*, Nicole Weeks, Alexander Wearing, Piers Duncan and Wajma Ebrahimi
}

Psychology Department, Macquarie University, NSW 2109, Australia

\begin{abstract}
In the past decade official reports into intelligence failures have asserted that analysts are subject to the effects of everyday cognitive limitations. The present study examined the influence of an individual's inclination toward closedmindedness on a computer administered simulated intelligence analysis task. Results indicate that several components of closed-mindedness as measured by the need for cognitive closure scale [NFC] significantly predicted the assessed level of threat posed to and general attitude toward a visiting government delegation by a foreign nation's population. Most significantly higher scores on the NFC subscale 'need for predictability' were associated with higher scores on the initial assessed threat level. This effect remained after controlling for the amount of information accessed. The implications of these findings for the conduct of intelligence analysis are discussed.
\end{abstract}

Keywords: Intelligence analysis, Closed-mindedness, Need for Cognitive Closure.

\section{INTRODUCTION}

Western democracies in the $21^{\text {st }}$ century have been forced to confront a resurgent threat from terrorists whose actions have fundamentally challenged the efficacy of existing national security systems, including long-practiced methods of intelligence collection and analysis. The present adversary is not a nation state and so is relatively elusive and adaptive. As a result of a number of intelligence failures the agencies charged with the responsibility of providing forewarning to governments to prevent attacks have been the subject of official inquiries [1-3] that have identified problems with the quality, timeliness and reliability of the assessments provided. One of the sources of these problems identified in these reports is the reasoning of intelligence analysts. Problems identified included group-think and a lack of questioning of assumptions referred to generally as biases.

It must however be recognized that an intelligence analyst's task is complex and demanding. Analysts are charged with identifying, selecting, analyzing and judging information that is relevant to the assessment of a potential threat. This task is carried out in an environment that is characterized by uncertainty, ambiguity, deception, time pressure and high stakes outcomes. Thus the context in which intelligence analysts' work is very likely to have an impact on reasoning skills. In addition to these contextual factors forty years of research into human reasoning and thinking generally has demonstrated that even rational, intelligent, competent adults, who are not under the pressure on intelligence analysts, are prone to errors and biases in their thinking $[4,5]$

*Address correspondence to this author at the Psychology Department, Macquarie University, NSW 2109, Australia; Tel: +61 (0)2 98508600;

Fax:+61 (0)2 98508062; E-mail: colin.wastell@mq.edu.au that can have a severe impact on their judgments. Recently researchers in this field have offered some suggestions on how reasoning and thinking research could make a contribution to the intelligence analysis profession [6]. Many of these suggestions focus on minimizing the effect of common cognitive limitations. However, in order to remediate the impact of common cognitive limitations on intelligence analyst work we must first be able to accurately specify the manner in which these limitations impact on intelligence tasks. Only then can specific interventions be designed and implemented.

\section{Human Information Processing; Biases and Predisposi- tions}

Cognitive limitations can be divided into the two broad categories of biases and predispositions. The number of biases and predispositions identified in the literature is quite large. The difference between a bias and a predisposition is one of coverage. Biases distort information processing in a systematic way that result in errors of judgment due to faulty perception of a specific situation while predispositions act as global frameworks for an individual's approach to thinking and problem solving generally. Examples of biases include anchoring and adjustment [7], representativeness [8] and confirmation bias [9]. Examples of predispositions include decision-making competence [10], need for cognition [11] and openness to experience [12]. For the purposes of the present paper we will concentrate on the predisposition that has been examined in the context of investigative tasks known as closed-mindedness [13]. The remainder of the paper is divided into three parts. Firstly we briefly outline the concept of closed-mindedness as measured using the need for cognitive closure scale [NFC], secondly we review research that has applied the closed-mindedness concept to an 
important intelligence failure before thirdly presenting our own empirical investigation of the impact of closedmindedness in a simulated intelligence analysis task.

\section{Closed-Mindedness and the Need for Cognitive Closure}

Kruglanski conceptualizes closed-mindedness [14] as a means to manage the possibility of being overwhelmed by incoming information. He [15] asserts that individuals generate and validate hypotheses with a view to accumulating a store of knowledge. This store of knowledge provides a frame of reference that gives confidence and reduces uncertainty. In developing this store of knowledge individuals have to manage a potentially overwhelming amount of information and this is accomplished by closing off selection either at intake or by stopping processing at some point. Kruglanski has defined closed-mindedness as 'a desire for a definite answer to a question, as opposed to uncertainty, confusion, or ambiguity' [13, p,84]. According to Kruglanski individuals high on closed-mindedness will abhor chaos and disorder, experience affective discomfort in the presence of ambiguity, and an urgent desire to reach closure. Kruglanski asserts that for many problems or tasks information processing can be interminable. In the absence of a strict deadline a moderate level of closed-mindedness will enable a stop to occur in information processing. When exactly the processing will stop depends on the level of closed-mindedness. Some degree of closed minded behavior is beneficial. A stopping rule must be found for each task in which there is no obvious conclusion to the process. Closed-mindedness can be seen as an element of human reasoning that in moderate levels is necessary for successful reasoning. It is when closed-mindedness reaches high levels that problems can occur.

Webster and Kruglanski [16] have identified 5 dimensions to the closed-mindedness construct. They are: 1) seeking of order; 2) a drive to resolve ambiguity; 3 ) the desire to come to a decision; 4) a preference for knowledge stability; and 5) acting to achieve a settled position. A closedmindedness psychological instrument has been developed to assess the level of each dimension that characterizes an individual. Table 1 shows the subscales of the Closedmindedness instrument and the goals they each address.

In examining the impact of closed-mindedness on knowledge generation and acquisition Kruglanski has identified two outcomes. He states that an individual with a high level of closed-mindedness will "experience a sense of urgency about reaching closure.. (and).. once initial closure was formulated adhere to it come what may" [14, p.14]. Kruglanski has termed these two dispositions seizing and freezing [17].

Kruglanski states that high closed-mindedness is not synonymous with political conservatism or a predisposition to evaluating situations in a pessimistic manner. In essence high closed-mindedness is a tendency to cease seeking additional information once a preferred position is adopted by an individual. The preferred position adopted may result from an individual's prior beliefs, the consensus that is currently dominant in an organization within which the individual works or other factors such as ideological views of a society more generally. Whatever the origin of the preferred position, close-mindedness results in a reduction or even cessation in seeking information. And what information is accessed is interpreted in terms of the preferred position.

Following extensive empirical work he has identified five consequences of heightened seizing and freezing which may “a) reduce the extent of information processing and hypothesis generation... b) elevate judgmental confidence... c) focus the information search on prototypical rather than diagnostic evidence... d) effect the use of early cues giving rise to impressional primacy... e) induce the tendency to exhibit correspondence or over attribution biases" [17, p.278]. These tendencies could have negative effects in many applied settings such as medical diagnoses, financial analysis, and security and defence intelligence analysis. In the domain of intelligence analysis the consequences of cognitive and personality predispositions such as closed-mindedness influencing threat estimates away from that warranted by the available data is at best highly problematic and at worst catastrophic [18]. We now turn to a study that explored the impact of high closed-mindedness on a major intelligence analysis failure.

\section{Closed-mindedness and the Yom Kippur War of 1973}

Bar-joseph \& Kruglanski [18] have analysed the Yom Kippur war of 1973 using the concept of closed-mindedness as operationalized using the Need for Cognitive Closure scale components [but not the scale itself]. This study was conducted using a qualitative analytic approach of archival material. Bar-Joseph and Kruglanski examined the situation within the Israeli Intelligence apparatus and speculate that managers displayed high closed-mindedness in their management behaviors which directly impacted upon the advice given to the Israeli government and lead to poor preparations

Table 1. Components of the Closed-mindedness Construct and NFC Scale

\begin{tabular}{|c|c|c|}
\hline Dimension & Goal & Sub-scale Name \\
\hline \hline Seek Order & Avoid chaos and disorder & Need for Order \\
\hline Resolve ambiguity & Reduce or avoid the affective discomfort induced by ambiguity & Intolerance of Ambiguity \\
\hline Come to a decision & Desire to reach closure & Need for Decisiveness \\
\hline Knowledge stability & Seek trans-situational-consistency & Need for Predictability \\
\hline Settled position & Desire for secure closure in which knowledge is not challenged & Closed-mindedness \\
\hline
\end{tabular}


on the part of the $\operatorname{IDF}^{1}$ for a war with Egypt ${ }^{2}$. They note that the Israeli intelligence failure was not the result of a lack of information but an "incorrect comprehension of the meaning of the available information" [18, p.77]. This lack of comprehension was evident in the Israeli military intelligence organisation, the Agaf HaModi'in (abbreviated as AMAN), the IDF and the Israeli government in that assumptions were not questioned (e.g. the capacity of the Egyptian army to effectively attack the IDF) and discrepant information was not investigated (e.g. reports from the front which indicated large scale movements of the Egyptian army). Bar-Joseph \& Kruglanski [18] assert that the schemas used by intelligence analysts and managers ${ }^{3}$ generated a threat assessment of the situation that was much less urgent than warranted by the available data. They assert that the assessment that was provided to the Israeli government was one that satisfied the closed-mindedness predispositions of the command elements of AMAN. The preferred position of the managers of AMAN was that there would not be an attack. Bar-Joseph \& Kruglanski [18, p.81] summarise the consequences of high closed-mindedness as; 1 . Reluctance to consider novel information that conflicts with 'frozen' view, 2. Reinterpretation of inconsistent information to suit the accepted view, 3 . Premium was placed on clarity, order and coherence, 4. Poor appreciation of alternative perspectives, 5 . Self- assuredness, 6. Intolerance of pluralism, and 7. Authoritarian style of leadership and decision making. For example, in terms of a 'frozen' view (that is one that is not allowed to be challenged) it was asserted that Egypt was not capable of defeating the IDF based on the success of the IDF in the Six Day war of 1967. This lead to the dismissal of frontline intelligence reports that indicated that there was an Egyptian build up as even if there was such a build up the Egyptian army could not win. An emphasis on clarity and resistance to change, even in the face of strong contrary evidence was detected by Bar-Joseph and Kruglanski in the attitudes of the commanders. Finally a strong authoritarian style of leadership, which discounted the views of others, was said to be present. The findings of this study indicate that high levels of closed-mindedness can have disastrous consequences in the area of intelligence analysis.

One of the questions to arise from this study is how could AMAN, or any intelligence agency, minimize the chances of this type of problem happening again? While structural reforms, strongly recommended in the recent reports into intelligence failures, are a component of improving intelligence product output it is also critical to examine the role and functioning of individual analyst reasoning. Bar-Joseph and McDermott [19] emphasise that a focus on the personality and cognitive predispositions of analysts is crucial to minimising the chances of intelligence failures. They urge consideration of such aspects as an analyst's "levels of openness and tolerance of ambiguity (or need for cognitive closure) in order to overcome unconscious (or unmotivated) biases" [19, p.128]. We would assert that an examination of the individual contribution of the components of closed-mindedness will potentially identify specific opportunities to remediate

\footnotetext{
${ }^{1}$ Israeli Defence Force

${ }^{2}$ Israel did go on to defeat the Egyptian threat but it was a close run outcome.

${ }^{3}$ Head of Military Intelligence and the Estimator of Egyptian Affairs.
}

and minimise the negative effects of this predisposition on intelligence analyst reasoning. The data used in Bar-Joseph and Kruglanski's study was retrospective reports and interviews and was analysed using a qualitative methodology. These data were used to identify behaviour that the authors labelled as consistent with high closed-mindedness. We would note that this method did not allow the identification of which dimensions of closed-mindedness were active at the time that the analysis was occurring in the minds of the senior AMAN officers studied by Bar-Joseph and Kruglanski [18]. In order to gain a more fine grained understanding of the potential impact of each of the NFC components we have conducted an analogue study of an intelligence analysis type task to explore the role of each NFC dimension on an estimate of threat. The study reported in this paper utilizes the newly developed computer simulation of complex information environments designated ASP-SINTELLA ${ }^{4}$ [20] that allows researchers to explore the influence of cognitive variables on analytic tasks while tracking the information processing behaviour used. A fuller description of ASPSINTELLA is provided in the Appendix.

\section{STUDY}

\section{Aim}

The aim of this study was designed to investigate the impact of closed-mindedness on the estimation of the threat level posed to government officials visiting a fictitious country. This is a very common type of problem faced by intelligence analysts and government security organizations.

\section{Hypotheses}

Closed-mindedness is defined as "a desire for a definite answer to a question, as opposed to uncertainty, confusion or ambiguity" [13, p.84]. Kruglanski has elucidated this construct to include five sub-components that lead to a truncation of information accessing and processing. The findings of studies by Bar-Joseph \& Kruglanski [18] and Ask \& Granhag [21] show that high closed-mindedness results in problematic behaviors in complex, ambiguous, information environments. The present study is an exploratory investigation of the impact of closed-mindedness on an analogue intelligence analysis task. As such we explored the five components of the Need for Cognitive Closure scale to ascertain which components, if any, were predictive of information processing behaviours and analytic outcomes. We did not have any a priori hypotheses concerning the total NFC scale as we believe this to be premature at the early stage of the research in this domain. We hypothesized the following:

Hypothesis 1: Participants high on NFC five subscales tend to stop information processing sooner than those low in NFC five subscales and hence those participants high in NFC five subscales will open fewer information cells, both distinct and repeat than participants low on NFC.

Hypothesis 2: Participants high on NFC five subscales tend to seize and freeze and so process information less extensively $[14, \mathrm{p} .21]$ and hence will spend on average less

\footnotetext{
${ }^{4}$ ASP- SINTELLA stands for Analysis Simulation Project - Simulation of INTELLigence Analysis.
} 
time in information cells generally than participants low on NFC five subscales.

Hypothesis 3: A risk averse stance was primed in participants by emphasizing the assessment of threat and hazards that exist in the country. The priming process would have established a preferred position of potential threat. This priming will orient participants toward detecting threats and dangers in the information they access. Given the assertion that those high in closed-mindedness generate fewer hypotheses [see 14, p,22] it seems likely that high NFC participants will gather and interpret information as indicating higher threat levels compared to participants low in NFC. This is consistent with the desire to avoid chaos and disorder within their understanding of the situation that they are dealing with.

\section{METHOD}

\section{Participants}

This study was conducted with University students $(\mathrm{n}=40)$ from a wide range of disciplines (see Table 1) $(50 \%$ male) who were paid \$20 Australian for their time.

\section{Procedure}

Initially participants completed a set of computeradministered questionnaires listed under measures below. They were then required to write a report based on the information that they accessed from the ASP-SINTELLA Country Study information matrix (see Appendix A Figs 1 and 2). The tasking required participants to formulate a visit report that outlined the potential threat and necessary precautions for members of the government delegation travelling to a fictitious country [Parette]. Participants undertook the task from the perspective a newly appointed staff member within the relevant government department from which the visit is originating. As part of the report participants were required to provide a numerical estimation of the threat to the visiting party once in that country. The priming of participants toward a threat context is based on research that shows that threat "reduces both the motivation and capacity for information processing" [22, p.790] which are characteristics of closed-mindedness. Priming is a well established experimental methodology that creates in study participants particular mental states or predispositions which are transient but which enable psychological influences to be activated and explored. See Bargh and Chartrand [23] for an outline of the procedures and its benefits. The choice of emphasizing a threat context was adopted to mirror the common situation in which these sorts of assessment tasks are undertaken in government agencies. Since this study was designed to examine how individuals information processing behavior is impacted by certain cognitive predispositions no information concerning organizational history or agency viewpoint was included. Though these factors are of great interest they were not primed in this study. In addition participants were required to estimate the general level of acceptance of the visiting party of officials from Australia among the population of the fictitious country [Parette]. Participants had 40 minutes to complete the analysis task and write the report. There were a number of control variables that we thought would be di- rectly related to the completion of a cognitive task. We selected Conscientiousness and Need for Cognition as they seemed to us [see scale descriptions below] to be potential confounds of an activity such as a cognitive analysis that required the evaluation of information in a relatively demanding task such as a threat assessment. Both these variables are prima facie applicable to intelligence analysis work. We did not have specific hypotheses about these variables but merely wanted to control their potential influence in the study. We did not include other control variables due to the size of the sample which we set at 40 .

\section{Measures}

Need For Cognitive Closure (NFC). The NFC [24] is a 42-item self-report instrument designed to assess stable individual differences in the need for cognitive closure. Participants are required to rate the extent to which they agree with statements on a 6-point Likert scale ranging from 1 (Strongly disagree) to 6 (Strongly agree), reflecting a preference for closure (e.g., 'I'd rather know bad news than stay in a state of uncertainty') and statements reflecting a desire to avoid closure (e.g., 'I tend to put off making important decisions until the last possible moment'). High scores on NFC suggest a higher preference towards cognitive closure as evidenced by an aversion to ambiguity and greater motivation to make decisions quickly and resist changing decisions. NFC subscales measure motives for closed-mindedness, intolerance for ambiguity, desire for order, predictability and decisiveness. The mean NFC score in Kruglanski, Webster and Klem [24] was $3.7(\mathrm{SD}=.38)$. Both internal and test-test reliabilities are satisfactory (Cronbach's $\alpha=.84$ and test-retest= .86 , respectively). In this study we used a slightly modified version as recommended by Roets and van hiel [25]. In the present study the Cronbach alphas were all within acceptable limits.

Need for Cognition was measured using a shortened scale developed by Cacioppo \& Petty [26]. Responses were given on a scale of 1 (extremely uncharacteristic of you) to 5 (extremely characteristic of you) with higher scores indicating greater motivation to think through complex issues and greater enjoyment derived from doing so. The scale has been extensively researched and reliability coefficient alphas vary from 0.74 to 0.97 [16] and 0.87 in the current study.

NEO-FFI The NEO Five-Factor Inventory (NEO-FFI) was developed by Costa and McCrae [12] as a short form of the Revised NEO Personality Inventory (NEO-PI-R) form S, for use with clinical and normal adult samples. Responses are given on a scale of 1 (strongly disagree) to 5 (strongly agree). In the present study, only the Conscientiousness subscale was included as it is a widely used and well validated measure of personality from the NEO-FFI [12] with high scores indicating greater tendency to be careful, organised, and self disciplined. The coefficient alpha for the Conscientiousness scale is 0.81 and 0.80 in the current study.

\section{RESULTS}

\section{Descriptive Statistics}

As can be seen in Table 2 the data from the current study show considerable variability across the full array of vari- 
ables as shown by the ranges. Some participants opened all the available cells and others opened many cells a number of times (repeat cell openings). Report lengths were also highly varied ranging from 67 to 276 words. The main variables of threat level and attitude toward Australia were likewise highly varied ranging from 10 to 100 and 20 to 100 respectively. The skew and kurtosis of the distributions were acceptable thus enabling parametric statistical analysis to be carried out. NFC (total and subscales) were typical of a University population at NFC Total of 3.66 in the current sample compared to 3.67 in previous samples [16, p.1051].

\section{Correlations}

The correlation matrix for the variables in the study is presented in Table 3. For ease reading the significant correlations are in bold print and the cell is greyed. The Need For Closure subscale correlations are very interesting and are consistent with our approach to separate subscale analysis. The highest subscale $r$ is between Ambiguity and Decisiveness at 0.577 . All other subscale correlations are smaller with the closed-mindedness subscale not significantly correlated with any of the other subscales. As would be expected the correlations between cell open variables and time in cells are significant. The correlations of confidence with all variables were not significant and thus no further analysis with confidence was carried out.

\section{Analysis}

The exploratory nature of our study lead us to set the alpha at $\mathrm{p}=0.05$ or less. In order to balance the occurrence of type 1 and type 2 errors we chose to report results that were of at least medium effect size [that is Partial $\eta>0.06]$. The preferred position of the experimental participants was not directly assessed. The participants were required to write a 250 word report. In none of the reports did participants reject the orientation of the task ie a threat assessment.

\section{Hypothesis 1: High NFC Subscale Scores will Predict Fewer Cells Opened}

The five Need for Closure subscales were regressed separately on distinct cells opened and repeat cells opened. After model reduction the only variable that predicted Distinct cells opened was NFC subscale Closed-mindedness $[\mathrm{F}(1,38)$ $=4.11, \mathrm{p}=.050, \mathrm{R}^{2}=9.8 \%$, partial $\left.\eta^{2}=0.09\right]$. For every one unit increase in NFC Closed-mindedness, participants opened eight fewer distinct cells. None of the subscales were significant predictors of repeat cells opened. This is consistent with our first hypothesis in that higher scores on NFC Closed-mindedness were associated with opening fewer cells and hence accessed less information. The fewer cells opened the less likely the preferred position will be able to be challenged by new, possibly divergent knowledge.

Table 2. Participant Information Processing Behaviours ASP-SINTELLA Country Study

\begin{tabular}{|c|c|c|c|}
\hline Variable $(n=40)$ & Mean & SD & Range \\
\hline Distinct cells opened (/64) & 35.85 & 15.15 & $14-64$ \\
\hline Total cell openings & 60.75 & 27.76 & $20-112$ \\
\hline Time per cell (seconds) & 8.22 & 3.19 & $2.36-16.24$ \\
\hline Words in report & 214.28 & 45.79 & $67-276$ \\
\hline Confidence $^{1}$ & 72.75 & 16.75 & $25-100$ \\
\hline Threat Assessment $^{2}$ & 59.18 & 23.48 & $10-100$ \\
\hline Attitude to Australia ${ }^{3}$ & 55.46 & 20.30 & $20-100$ \\
\hline Order & 4.11 & 0.87 & $1.80-5.60$ \\
\hline Closed-mindedness & 2.83 & 0.61 & $1.50-4.25$ \\
\hline Ambiguity & 4.03 & 0.59 & $2.67-5.44$ \\
\hline Decisiveness & 3.54 & 0.84 & $1.67-5.17$ \\
\hline Predictability & 3.59 & 0.83 & $2.25-5.38$ \\
\hline $\begin{array}{l}{ }^{1} \text { Confidence in their threat estimate: } \\
{ }^{2} \text { Threat Assessment } \\
{ }^{3} \text { Attitude toward Australia } \\
\text { Gender: Male 50\% } \\
\text { Major Psychology } 30 \%\end{array}$ & $\begin{array}{l}0=\text { not at all confident } \\
0=\text { No threat } \\
0=\text { Very positive }\end{array}$ & $\begin{array}{l}100=\mathrm{Ex} \\
100=\mathrm{Ex} \\
100=\mathrm{Ve} \\
23 \%\end{array}$ & $\begin{array}{l}50 \% \text { Neutral } \\
\text { Unspecified } 15 \%\end{array}$ \\
\hline
\end{tabular}


Table 3. Correlation Matrix for Variables in the Study

\begin{tabular}{|c|c|c|c|c|c|c|c|c|c|}
\hline & & \multicolumn{2}{|c|}{ CellsOpened } & $\begin{array}{r}\text { RepCellOpen } \\
.737^{* *} \\
\end{array}$ & $\begin{array}{r}\text { Timecell } \\
-.132 \\
\end{array}$ & $\begin{array}{r}\text { TimeInCells } \\
.754^{* *}\end{array}$ & $\begin{array}{r}\text { Q2threat } \\
-.401^{*}\end{array}$ & $\begin{array}{r}\text { attAus } \\
137 \\
\end{array}$ & $\begin{array}{r}\text { Q3conf } \\
-.103 \\
\end{array}$ \\
\hline Cells_opened & $\mathrm{N}$ & & 40 & 40 & 40 & 40 & 40 & 39 & 40 \\
\hline \multirow[t]{2}{*}{ RepCellOpenings } & Pearson & & $.737^{* *}$ & 1 & -.253 & $.683^{* *}$ & $-.336^{*}$ & -.177 & -.111 \\
\hline & $\mathrm{N}$ & & 40 & 40 & 40 & 40 & 40 & 39 & 40 \\
\hline \multirow[t]{2}{*}{ TimeInCells } & Pearson & & $.754^{* *}$ & $.683^{* *}$ & $.417^{* *}$ & 1 & $-.544^{* *}$ & .026 & -.063 \\
\hline & $\mathrm{N}$ & & 40 & 40 & 40 & 40 & 40 & 39 & 40 \\
\hline \multirow[t]{2}{*}{ Q2threat } & Pearson & & $-.401^{*}$ & $-.336^{*}$ & -.249 & $-.544^{* *}$ & 1 & -.282 & -.252 \\
\hline & $\mathrm{N}$ & & 40 & 40 & 40 & 40 & 40 & 39 & 40 \\
\hline \multirow[t]{2}{*}{ Q3confthreat } & Pearson & & -.103 & -.111 & .092 & -.063 & -.252 & .300 & 1 \\
\hline & $\mathrm{N}$ & & 40 & 40 & 40 & 40 & 40 & 39 & 40 \\
\hline \multirow[t]{2}{*}{ Age } & Pearson & & -.056 & .075 & $.352^{*}$ & .178 & .226 & -.194 & -.236 \\
\hline & $\mathrm{N}$ & & 40 & 40 & 40 & 40 & 40 & 39 & 40 \\
\hline \multirow[t]{2}{*}{ NFC } & Pearson & & .055 & .028 & -.227 & -.121 & .219 & -.173 & -.104 \\
\hline & $\mathrm{N}$ & & 40 & 40 & 40 & 40 & 40 & 39 & 40 \\
\hline \multirow[t]{2}{*}{ Order } & Pearsoo & & .107 & .068 & -.111 & -.032 & .112 & .011 & .195 \\
\hline & $\mathrm{N}$ & & 40 & 40 & 40 & 40 & 40 & 39 & 40 \\
\hline ClosedMnd & Pearson & & $-.313^{*}$ & -.262 & -.065 & -.306 & .259 & $-.329^{*}$ & -.299 \\
\hline \multirow[t]{2}{*}{ Predictability } & Pearson & & .065 & .027 & -.260 & -.137 & .310 & -.210 & -.051 \\
\hline & $\mathrm{N}$ & & 40 & 40 & 40 & 40 & 40 & 39 & 40 \\
\hline Age & NFC & Order & & ClsdMnd & Amb & & Decisive & & Predict \\
\hline-.056 & .055 & .107 & & $-.313^{*}$ & & .134 & & .114 & .065 \\
\hline 40 & 40 & 40 & & 40 & & 40 & & 40 & 40 \\
\hline .075 & .028 & .068 & & -.262 & & .197 & & .005 & .027 \\
\hline 40 & 40 & 40 & & 40 & & 40 & & 40 & 40 \\
\hline $.352^{*}$ & -.227 & -.111 & & -.065 & & -.269 & & -.042 & -.260 \\
\hline 40 & 40 & 40 & & 40 & & 40 & & 40 & 40 \\
\hline .178 & -.121 & -.032 & & -.306 & & .007 & & .034 & -.137 \\
\hline 40 & 40 & 40 & & 40 & & 40 & & 40 & 40 \\
\hline .226 & .219 & .112 & & .259 & & .029 & & .006 & .310 \\
\hline 40 & 40 & 40 & & 40 & & 40 & & 40 & 40 \\
\hline-.194 & -.173 & .011 & & $-.329^{*}$ & & -.029 & & -.100 & -.210 \\
\hline 39 & 39 & 39 & & 39 & & 39 & & 39 & 39 \\
\hline
\end{tabular}


Table 3. Contd.....

\begin{tabular}{|c|c|c|c|c|c|c|}
\hline Age & NFC & Order & ClsdMnd & Ambig & Decisive & Predict \\
\hline 40 & 40 & 40 & 40 & 40 & 40 & 40 \\
\hline 1 & -.299 & -.038 & -.171 & $-.325^{*}$ & $-.392^{*}$ & -.187 \\
\hline 40 & 40 & 40 & 40 & 40 & 40 & 40 \\
\hline-.038 & $.729^{* *}$ & 1 & -.073 & .298 & .276 & $.538^{* *}$ \\
\hline 40 & 40 & 40 & 40 & 40 & 40 & 40 \\
\hline-.171 & $.336^{*}$ & -.073 & 1 & .167 & .265 & .060 \\
\hline 40 & 40 & 40 & 40 & 40 & 40 & 40 \\
\hline 40 & 40 & 40 & 40 & 40 & 40 & 40 \\
\hline-.187 & $.773^{* *}$ & $.538^{* *}$ & .060 & $.383^{*}$ & $.425^{* *}$ & 1 \\
\hline 40 & 40 & 40 & 40 & 40 & 40 & 40 \\
\hline
\end{tabular}

**. Correlation is significant at the 0.01 level (2-tailed).

*. Correlation is significant at the 0.05 level (2-tailed).

\section{Hypothesis 2: High NFC Subscale Scores will Predict Less Time in Cells}

Again the five Need for Closure subscales were regressed on average time spent in cells. None of the subscales were statistically significant predictors of average time per cell. Although, participants high on NFC subscales Predictability and Intolerance of Ambiguity tended to spend less time per cell on average.

\section{Hypothesis 3: High NFC Subscale Scores will Predict Higher Threat Levels}

Using a general linear modeling approach, regression analysis was carried out on predispositions including NFC subscales, Need for Cognition and NEO FFI Conscientiousness, background variables (e.g. gender), and behavioural variables (e.g. number of distinct cells opened). After model reduction only gender, NFC subscale Need for Predictability, and the number of cells opened predicted threat estimates $\left[\mathrm{F}_{(3,36)}=7.31, \mathrm{p}=.001, \mathrm{R}^{2}=38 \%\right.$, Partial $\left.\eta^{2}=0.14\right]$. Females on average, produced threat estimates 15 percentage points higher than males. A one unit increase in NFC Need for Predictability predicted a 9 percentage point increase in threat assessment. The goal of knowledge stability as seen in NFC Need for Predictability (see Table 1) predicting threat levels is an interesting finding as the association of knowledge and threat level is not theoretically obvious and calls for further investigation. Finally for every 10 distinct initial cells opened threat assessment decreased by 7 percentage points. This result is consistent with the prediction of the impact of NFC Predictability on threat estimates. When all other variables are controlled for NFC Predictability is a substantial predictor of assessed level of threat when partici- pants have been primed with a threat perspective. Put another way high scores on NFC Predictability predict more negative threat estimates over and above the accessed information. The results for gender and number of cells opened are interesting in that females seem more threat orientated and the more cells opened the more moderated is the threat estimate.

As a result of the findings regarding assessed level of threat further analysis was conducted on the closely related concept of the perceived attitude of Parettians toward Australia generally. The same variables used in the previous analysis were regressed on attitude to Australia. Perceived attitude towards Australia was predicted by the three variables, NFC subscale Closed-mindedness, cells opened, and repeat cell openings $\left[\mathrm{F}_{(3,35)}=4.77, \mathrm{p}=.007, \mathrm{R}^{2}=29 \%\right.$, partial $\left.\eta^{2}=0.11\right]$. Participants one unit higher on NFC subscale closed-mindedness tended to perceive the Parettians' attitude toward Australia to be 11 percentage points more hostile. Opening more distinct cells lead to an estimation that was a more positive impression, in this case, with every 10 cells opened the attitude towards Australia became more positive by 7 percentage points. However, with every 10 repeat cell openings, attitude became less positive by 9 percentage points.

\section{DISCUSSION}

The findings of this study have a number of implications for professionals who carry out analysis in complex, ambiguous and uncertain information environments. Firstly the components of NFC have differential effects on information processing behavior. In the case of hypothesis 1 , which tentatively predicted that participants high in at least one NFC 
subscale would open fewer cells it was the closedmindedness component that was predictive of the number of cells opened, while none of the other NFC components were predictive. For hypothesis 2 , which tentatively predicted that participants high in at least one NFC subscale would spend less average time in cells, none of the NFC components reached the 0.05 criteria but nevertheless the effect size for NFC predictability component was medium at Cohen's d= 0.58 . Further research on NFC Closed-mindedness and depth of processing should be conducted to examine the potential relationship between these constructs.

The findings of this study also demonstrate that individual characteristics, predispositions and information gathering activity influence threat and attitude assessments. Generally, when participants accessed more information, their view of Parette became more positive as evidenced by decreased threat assessments and more positive perceived attitudes toward Australia. In other words more information is associated with less negativity within the context of a general predisposition toward threat as a starting point. Higher scores on NFC subscales of Need for Predictability and Closedmindedness were associated with more negative estimates as well as less information accessing behavior. This is consistent with Kruglanski's concepts of seizing and freezing. On theoretical grounds participants high in NFC Need for Predictability and Closed-mindedness are expected to seize on an early view and avoid or ignore information that conflicts with that view. Our results suggest that before any data is accessed analysts who are primed toward a negative mindset (threat and hazards in our study) and who are high on NFC Need for Predictability and Closed-mindedness subscales will be predisposed to more negative assessments than may be warranted by the data. This result is the reverse of what was found by Bar-Joseph and Kruglanski [18]. In direction but not in process. In both analyses high closed-mindedness predicted seizing and freezing on a view which was associated with less information processing. The training and development of all analysts should address the possibility of such predispositions as recommended by [18]. In our study the estimation of the level of threat and a general attitude toward the country of origin was also predicted by the cognitive predisposition over and above the information accessed.

There are several caveats that must be recognized with respect to our findings. Firstly we did not conduct this study with practicing intelligence analysts. This is an important caveat. Analysts generally do not come to a task as a blank slate. They have varying degrees of background information that will inform their assessments. However, our investigation was designed to separate knowledge levels from information processing. Further research with practicing analysts is necessary to examine the influence of prior knowledge on the quality of information processing and the potential impact of predispositions such as closed-mindedness. Also intelligence agencies often recruit from the population of university graduates and so the use of participants from a University population was appropriate in terms of the underlying skills and processes potential analysts bring to their profession. Secondly the time frame was short at only 40 minutes for the analytic task. There was no time for reflection, review and revision. This condition however is not uncommon within intelligence agencies when time is short. Thirdly as discussed previously phrasing the task as a threat assessment may have influenced participants high in NFC subscales Closed-mindedness and Need for Predictability to seize on the view that Parette was dangerous and biased their information search accordingly. Fourthly the analysis was undertaken by individuals with no option for group discussion. These limitations suggest potential areas for future research.

\section{Implications for Tradecraft and Training of Intelligence Analysts}

The implications of the findings of the present study for organizations that rely on intelligence analysis deserve serious consideration. These organizations include Police, Military and Security services. If the findings are replicated within such a specialist population then the argument for incorporating the implications of our study for training and practice becomes compelling. In the case of the cognitive predisposition of closed-mindedness, experience alone could not then be claimed to eliminate the problematic effects of this cognitive predisposition. The implication of our investigation is that seizing and freezing on a preferred position both reduced the accessing of information and biased the interpretation of the information that is accessed. Training and tradecraft must be designed to minimize the effects of closed-mindedness. Procedures must be developed so that the analyst can concentrate on the task and not on trying to avoid falling prey to any particular bias or predisposition. The development of such procedures for combating the negative effects of closed-mindedness will need to address the tendency to reduce information processing and limited hypothesis generation. An example of a procedure to address a potentially problematic cognitive predisposition is the relatively recent attempt to minimize the effects of confirmation bias developed by Heuer [27]. The Analysis of Competing Hypotheses (ACH) methodology is designed to address confirmation bias by enabling analysts to represent a number of hypotheses and collate the evidence that is adduced to support each hypothesis. This is a good example of a process that can help address a bias through structuring the analytical process so that analysts can focus their attention on the intelligence task at hand and not on avoiding committing the bias.

\section{CONCLUSION}

The results of this study add to other research [19, 28-30] that point to the need to address the issue of the influence of cognitive biases and predispositions in domains such as security and intelligence analysis. This will require a great deal more research specifically involving the members of the intelligence community. In domains such as intelligence analysis with such important and far reaching consequences it would seem prudent to consider this research as a high priority.

\section{CONFLICT OF INTEREST}

The author(s) confirm that this article content has no conflicts of interest.

\section{ACKNOWLEDGEMENT}

None declared. 


\section{APPENDIX}

\section{The Analysis Simulation Project}

The Analysis Simulation Project (ASP) set out to develop a computer-mediated simulation of complex, dynamic, ambiguous and uncertain information environments. These environments are encountered by many professions but especially by intelligence analysts where adversaries are intent on hiding their real intentions and the volume of information is vast. The ASP program consist of a matrix of $64(8 \times 8)$ cells of text based information (see Fig. 1). The generation of 64 cells simulates the substantial amount of information encountered by analysts with the aim of making it very difficult for to recall all of it. The behaviour of study participants can be tracked including cells opened (including number of times a cell is re-opened), how long (in milliseconds) each cell is open, which material is copied and pasted onto a workspace and which material is used in a final report. Experiments are constructed using realistic scenarios that require participants to complete a task. Two variants of ASP SINTELLA have been produced. They are ASP SINTELLA - Country Study and ASP SINTELLA - Murder Investigation. The current paper describes an experiment carried out using the ASP SINTELLA - Country Study variant.

\section{ASP SINTELLA - Country Study}

The Country study version was designed to simulate the intelligence analysis environment where analysts are required to gather information on a particular country in order to prepare a report for senior officers. Fig. (1) shows the Country Study screen with information categories and workspaces. Information categories were selected to cover those topics that are of interest to security and military agencies in the preparation of intelligence products, for example infrastructure, economy and politics.

Fig. (2) is an example of the content of an information cell (specifically from the End of Apartheid cell in the History: Current and Past column). The fictitious country is named Parette. Analysts must use their judgment to estimate the level of threat $[0=$ no threat to $100=$ extreme threat] and produce a report that both informs the senior officer [i.e. the target audience of the tasking] and justifies the threat estimate.

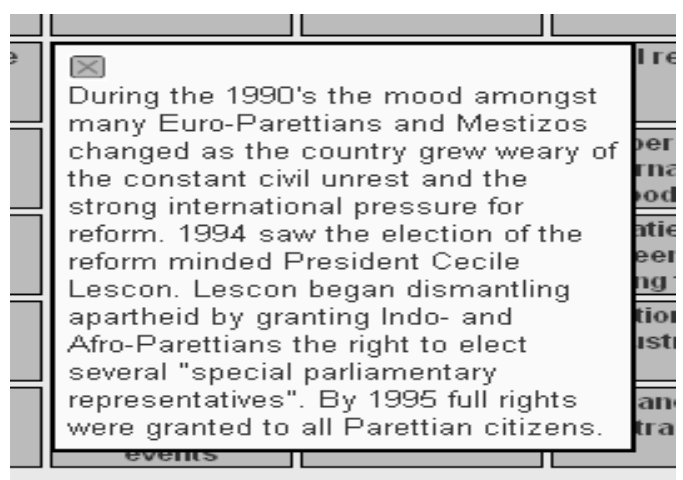

Fig. (2). ASP-SINTELLA Country Study content from the cell End of Apartheid

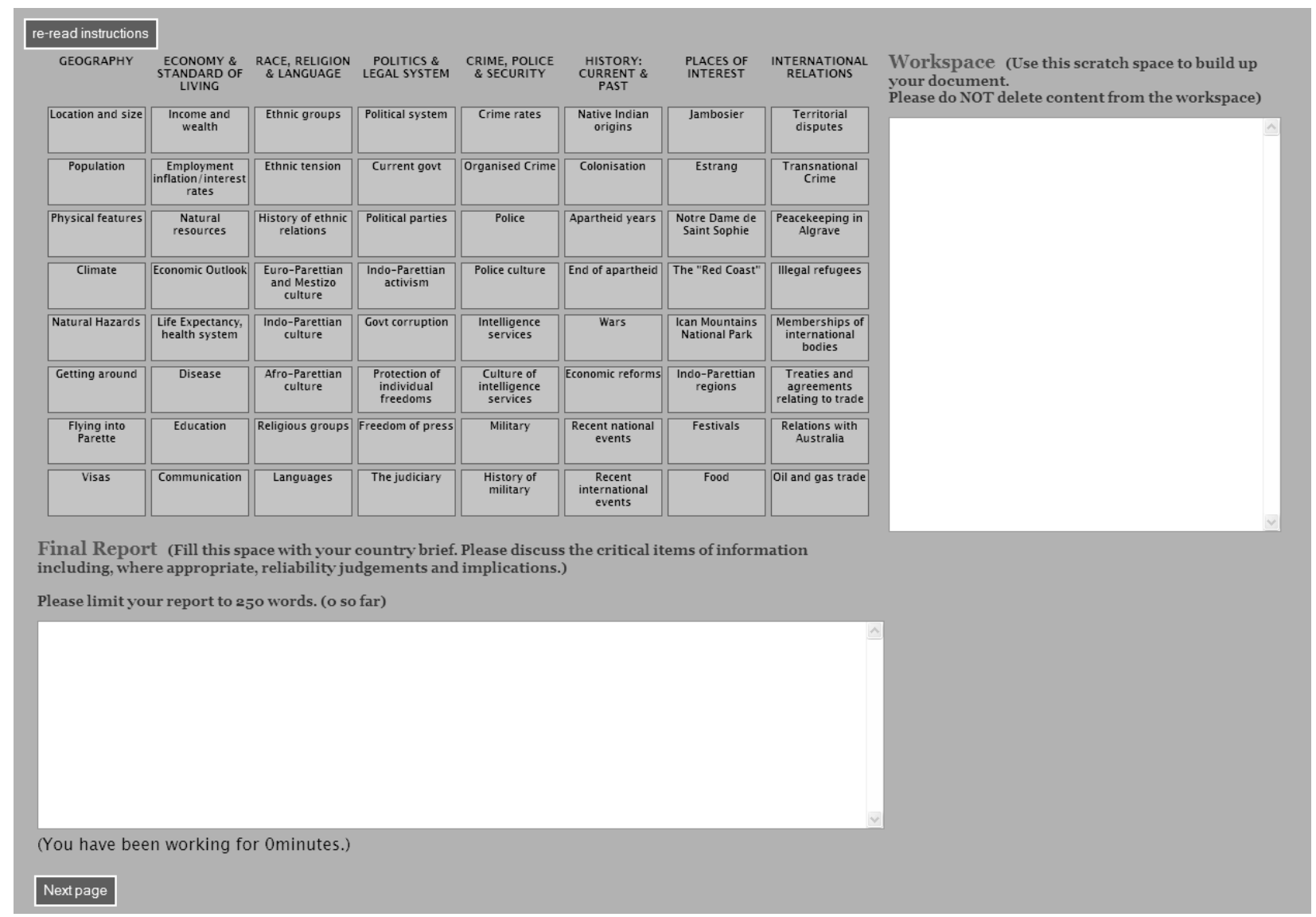

Fig. (1). Country Study Version of ASP-SINTELLA 
The program measures the depth, breadth and type of information that participants access, what information is selected (as indicated by text copied to the workspace and report).

\section{REFERENCES}

[1] Flood P. Report of the inquiry into Australian Intelligence Agencies. (Canberra: Commonwealth of Australia) 2004. [Retrieved April 21, 2006], Available from http://www.dpmc.gov.au/publications/intelligence_inquiry/do/intelligence_report.pdf

[2] Butler L. Review of intelligence of weapons of mass destruction. (London: House of Commons) 2004. [Retrieved 21 April, 2006], Available from http://www.butlerreview.org.uk/report/index.asp

[3] National Commission on Terrorist Attacks upon the United States. The 9/11 Commission Report: Final Report of the National Commission on Terrorist attacks upon the United States, (New York: W. W. Norton) 2004. [Retrieved April 21, 2006], Available from http://www.911 commission.gov/report/911Report.pdf

[4] GilovichT, Griffin D, Kahneman D. Heuristics and biases: the psychology of intuitive judgment. Cambridge, UK: Cambridge University Press 2002.

[5] Ariely D. Predictably irrational. New York: Harper 2008.

[6] National Research Council. Intelligence Analysis for Tomorrow: Advances from the Behavioral and Social Sciences. Washington, DC: The National Academies Press 2011.

[7] Chapman G. Bornstein B. The more you ask for the more you get: Anchoring in personal injury verdicts. Appl Cogn Psychol 1996; 10: 519-40.

[8] Kahneman D, Tversky A. Subjective probability: a judgment of representativeness. Cogn Psychol 1972; 3: 430-54.

[9] Klayman J. Varieties of confirmation bias. Psychol Learn Motiv 1995; 32: 385-418.

[10] Bruine de Bruin W, Parker A, Fischhoff B. Individual differences in adult decision-making competence. J Pers Soc Psychol 2007; 92: 938-56.

[11] Cacioppo J, Petty R, Feinstein J, Jarvis W. Dispositional differences in cognitive motivation: the life and times of individuals varying in need for cognition. Psychol Bull 1996; 119: 197-253.

[12] Costa P, McCrae R. Professional Manual for the Revised NEOPersonality Inventory (NEO-PI-R) and NEO Five-Factor Inventory (NEO-FFI). Odessa, FL: Psychological Assessment Resources Inc 1992.

[13] Kruglanski A, Chun W. Motivated closed-mindedness and its social consequences. In: Shah JY, Gardner WL, Eds. Handbook of Motivation Science. New York: Guilford Press 2008; pp. 84-99.
[14] Kruglanski A. The psychology of closed-mindedness. New York: Psychology Press 2004.

[15] Kruglanski A. Lay epistemic theory in social-cognitive psychology. Psychol Inq 1990; 1: 181-97.

[16] Webster D, Kruglanski A. Individual differences in need for cognitive closure. J Pers Soc Psychol 1994; 67: 1049-62.

[17] Kruglanski A, Webster D. Motivated closing of mind: "Seizing" and "Freezing". Psychol Sci 1996; 103: 263-83.

[18] Bar-Joseph U, Kruglanski A. Intelligence failure and need for cognitive closure: On the psychology of the Yom Kippur Surprise. Polit Psychol 2003; 24: 75-99.

[19] Bar-Joseph U, McDermont R. Change the analyst and not the system: A different approach to intelligence reform. Foreign Policy Ref 2008; 4: 127-45.

[20] Weeks N, Wastell C, Taylor A, Wearing A, Duncan P. Tracing decision processes in complex, ambiguous, information-rich environments. Int J Psychol Stud 2012; 4(1): 158-73.

[21] Ask K, Granhag P. Motivational sources of confirmation bias in criminal investigations: The need for cognitive closure. J Invest Psychol Offend Prof 2005; 2: 43-63.

[22] Thorisdottir H, Jost J. Motivated closed-mindedness mediates the effect of threat on political conservatism. Polit Psychol 2012; 32: 785-811.

[23] Bargh JA, Chartrand TL. The mind in the middle: A practical guide to priming and automaticity research. In: Reis HT, Judd CM, Eds. Handbook of research methods in social and personality psychology. New York: Cambridge University Press 2000; pp. 214-59.

[24] Kruglanski A, Webster D, Klem A. Motivated resistance and openness to persuasion in the presence or absence of prior information. $\mathrm{J}$ Pers Soc Psychol 1993; 65: 861-76.

[25] Roets A, Van Hiel A. Separating ability from need: clarifying the dimensional structure of the need for closure scale. Pers Soc Psychol Bull 2007; 33: 266-80.

[26] Cacioppo J, Petty R. The need for cognition. J Pers Soc Psychol 1982; 42: 116-31.

[27] P. A. R. C., Heuer R. ACH tutorial 2006. [Retrieved March, 2009], Available from http://www2.parc.com/istl/projects/ach/ach.html.

[28] Wastell C, Clark G, Duncan P. Effective intelligence analysis: The human dimension. J Policing Intell Counter Terror 2006; 1: 36-53.

[29] Tetlock P. Expert Political Judgment: How good is it? How can we know? New Jersey, USA: Princeton University Press 2005.

[30] Wastell C, Weeks N, Duncan P. SINTELLA: Simulation of INTELLigence Analysis. J Policing Intell Counter Terror 2009; 4: 7181.

Received: August 09, 2013

Revised: August 16, 2013

Accepted: August 16, 2013

(C) Wastell et al.; Licensee Bentham Open.

This is an open access article licensed under the terms of the Creative Commons Attribution Non-Commercial License (http://creativecommons.org/licenses/ by-nc/3.0/) which permits unrestricted, non-commercial use, distribution and reproduction in any medium, provided the work is properly cited. 